\title{
Correction to: Cryopreservation of Potato Shoot Tips for Long-Term Storage
}

\section{Rainer Vollmer, Janeth Espirilla, Rosalva Villagaray, José Cárdenas, Mario Castro, Juan Carlos Sánchez, Norma Manrique-Carpintero, David Ellis, and Noelle Lynette Anglin}

Correction to:

Chapter 2 in: David Dobnik et al. (eds.), Solanum tuberosum:

Methods and Protocols, Methods in Molecular Biology, vol. 2354, https://doi.org/10.1007/978-1-0716-1609-3_2

Chapter 2 was previously published non-open access. It has now been changed to open access under a CC BY 4.0 license, and the copyright holder updated to 'The Author(s)'. The book has been updated with this change.

The updated online version of this chapter can be found at https://doi.org/10.1007/978-1-0716-1609-3_2 